\title{
Heated communities: large inter- and intraspecific variation in heat tolerance across trophic levels of a soil arthropod community
}

\author{
Oscar Franken ${ }^{1}\left[\right.$ Milou Huizinga ${ }^{1} \cdot$ Jacintha Ellers ${ }^{1} \cdot$ Matty P. Berg $^{1,2}$
}

Received: 2 August 2017 / Accepted: 29 November 2017 / Published online: 9 December 2017

(c) The Author(s) 2017. This article is an open access publication

\begin{abstract}
Temperature extremes are predicted to increase in frequency, intensity and duration under global warming and are believed to significantly affect community composition and functioning. However, the effect of extreme climatic events on communities remains difficult to predict, especially because species can show dissimilar responses to abiotic changes, which may affect the outcome of species interactions. To anticipate community responses we need knowledge on within and among species variation in stress tolerance. We exposed a soil arthropod community to experimental heat waves in the field and measured heat tolerance of species of different trophic levels from heated and control plots. We measured the critical thermal maximum $\left(\mathrm{CT}_{\max }\right)$ of individuals to estimate inter- and intraspecific variation in heat tolerance in this community, and how this was affected by experimental heat waves. We found interspecific variation in heat tolerance, with the most abundant prey species, the springtail Isotoma riparia, being more sensitive to high temperatures than its predators (various spider species). Moreover, intraspecific variation in $\mathrm{CT}_{\max }$ was substantial, suggesting that individuals within a single species were unequally affected by heat extremes. However, heat tolerance of species did not increase after being exposed to an experimental heat wave. We conclude that interspecific variation in tolerance traits potentially causes trophic mismatches during extreme events, but that intraspecific variation could lessen these effects by enabling partial survival of populations. Therefore, ecophysiological traits can provide a better understanding of abiotic effects on communities, not only within taxonomic or functional groups, but also when comparing different trophic levels.
\end{abstract}

Keywords Critical thermal maximum $\left(\mathrm{CT}_{\max }\right) \cdot$ Extreme event $\cdot$ Heat wave $\cdot$ Functional trait $\cdot$ Thermal stress

Communicated by Sylvain Pincebourde.

We expanded the use of trait-based approaches to include multiple taxa within a soil arthropod community in the field. This provides new insights on how differences in tolerance can shape communities.

Electronic supplementary material The online version of this article (https://doi.org/10.1007/s00442-017-4032-z) contains supplementary material, which is available to authorized users.

Oscar Franken

oscarfranken@gmail.com; o.franken@vu.nl

1 Section of Animal Ecology, Department of Ecological Science, Vrije Universiteit, Amsterdam, De Boelelaan 1085, 1081 HV Amsterdam, The Netherlands

2 Groningen Institute for Evolutionary Life Sciences, Community and Conservation Ecology Group, University of Groningen, PO Box 11103, 9700 CC Groningen, The Netherlands

\section{Introduction}

Most terrestrial ecosystems irregularly experience sudden and severe changes in environmental conditions, for example, due to extreme weather events, such as heat waves, drought spells, and floods. Such extreme events have recently received increasing experimental attention (e.g., De Boeck et al. 2011; Krab et al. 2013; Kayler et al. 2015), but their impact on the community relative to more gradual changes in abiotic conditions remains hard to assess. Whereas, extreme events occur infrequently and usually last for a short period of time, they impose more extreme conditions on organisms and the sudden onset of these events leaves little time for adaptation. Moreover, current climate change scenarios predict an increase in frequency, intensity and duration of extreme weather events (Easterling et al. 2000a, b; Beniston et al. 2007; Rahmstorf and Coumou 2011), which may amplify their ecological impact (Gutschick and BassiriRad 2003; Jentsch et al. 2007). 
A major challenge in community ecology is to predict the effects of such extreme weather events on community structure and composition (Gilman et al. 2010; Sutherland et al. 2013). The main difficulty in anticipating a community response is that different species within the community can show dissimilar responses to abiotic stress, which may be due to differences in physiological tolerances or behavioural strategies and microhabitat use to avoid stress. In addition, the variation among species in their responses to environmental change may result in altered trophic, competitive or facilitative interactions and interaction strengths (Tylianakis et al. 2008; Walther 2010; Berg et al. 2010). To anticipate community responses we need knowledge on interspecific and intraspecific variation in responses of species to abiotic stress, which can be investigated using functional traits that relate to species tolerance.

Trait-based approaches have been advocated as a more mechanistic approach to foresee how communities are affected by environmental change (McGill et al. 2006; Langlands et al. 2011; Dias et al. 2013). Multiple studies have related variation in tolerance traits and their environmental drivers to spatial distribution of species (Dias et al. 2013; van Dooremalen et al. 2013), (dis)assembly processes (Lindo et al. 2012; Bartlett et al. 2016), and community composition (Bokhorst et al. 2012). However, trait studies have mainly been carried out within single functional groups or trophic levels (e.g., Dias et al. 2013; van Dooremalen et al. 2013), rather than across trophic levels within a single community (but see Sentis et al. 2013; Puentes et al. 2015). Moreover, studies have predominantly used mean trait values of species to characterize interspecific variation in tolerance, ignoring the fact that trait distributions between species may overlap due to intraspecific variation of trait values (Albert et al. 2011; Violle et al. 2012). Intraspecific variation in stress tolerance determines the relative proportion of a population that will be affected by the extreme conditions and the proportion that can still interact with other species. Thus, including within-species variation in trait-based studies predicting community responses is imperative, as previously shown for Collembola (Janion et al. 2009).

Intraspecific variation of trait values can be caused by several underlying mechanisms, and these may differentially affect persistence under extreme conditions. For instance, many species show ontogenetic variation in traits related to abiotic stress, which affects survival probabilities of different life stages (Bowler and Terblanche 2008; Hoffmann 2010; Kingsolver et al. 2011; Nakazawa 2014; Zizzari and Ellers 2014). Especially when extreme conditions affect only a particular age or size class, such as small-sized juveniles or reproductively active adults, severe consequences for the population can be expected. This may alter size distributions and population dynamics with cascading effect on higher trophic levels (e.g., through reduced prey density) or lower trophic levels (e.g., through reduced predation pressure). Another important source of intraspecific variation in trait values is phenotypic plasticity (DeWitt and Scheiner 2004), by which previous exposure to stressful conditions may lead to a rapid increase in tolerance to subsequent exposures, which may even act across generations (e.g., Bateson et al. 2014; Zizzari et al. 2016). Moreover, if species differ in the degree to which they adjust their physiology to extreme conditions, this may differentially affect species' survival when exposed to extreme events, thereby affecting the interaction strength between the species. Understanding the causes and consequences of intraspecific variation can provide valuable insight in the effects of extreme events at the population level, and subsequently on the interactions with other species in the community.

In this paper we investigate the extent of inter- and intraspecific variation in heat tolerance of several species from a soil arthropod community that was exposed to experimental heat waves. These heat waves were induced by placing small plastic greenhouses with heat emitters in the field. We focus on a thermal trait that is related to temperature extremes: the critical thermal maximum $\left(\mathrm{CT}_{\max }\right)$, which reflects the heat tolerance of an individual when exposed to a gradually increasing temperature (Lutterschmidt and Hutchison 1997; Terblanche et al. 2007; Mitchell and Hoffmann 2010). As $\mathrm{CT}_{\max }$ is measured at the individual level, this tolerance proxy allowed us to measure intraspecific variation in heat tolerance and link this to body size effects. Using species from a single arthropod community, we maximize the likelihood that they have previously experienced the same climatic conditions, although the actual habitat mean temperature and variance that individuals have experienced is likely to be modified by behavioural differences and microhabitat use.

We expected to find interspecific differences in heat tolerance due to differences in physiology among species, especially because thermal traits are often considered to be phylogenetically conserved (e.g., Kellermann et al. 2012; Araújo et al. 2013). We further expected large intraspecific variation within the measured species, mostly due to differences in body size and associated ontogenetic variation. Specifically, we hypothesize that larger, adult individuals are more sensitive to exposure to high temperatures than smaller, juvenile individuals (Bowler and Terblanche 2008; Zizzari and Ellers 2014). Finally, we expected an increase in heat tolerance of species after being exposed to an artificial heat wave in the field, either because of phenotypic plasticity in heat tolerance or because of disproportional survival of more tolerant individuals. We will discuss the ecological consequences of the inter- and intraspecific variation in heat tolerances in terms of species interactions within our soil community. 


\section{Materials and methods}

\section{Field site}

Our experiment was conducted on the southwest side of the barrier island of Schiermonnikoog $\left(53.46896^{\circ} \mathrm{N}\right.$, $\left.6.13914^{\circ} \mathrm{E}\right)$, The Netherlands. The ecosystem consisted of a vegetated beach which was characterized by a rather low diversity of plant species and a relatively low species richness of the arthropod community compared to other terrestrial ecosystems (van Wingerden and den Hollander 1981; Ellers et al. 2011). This allowed us to collect individuals from all the dominant taxa living on the soil surface and include them in our study. The study site was located $\sim 400 \mathrm{~m}$ north of the mean high tide line, in an area which annually received about five to ten sea water inundation events. During our experiment, there were no inundation events. The vegetation was dominated by Glaux maritima L. with tufts of Carex extensa Gooden, C. distans L. and Limonium vulgare Mill. Approximately the first $\mathrm{cm}$ of the soil consisted of sand mixed with fine organic matter with almost no build-up of a leaf litter layer. In patches where vegetation cover was sparse, a microbial mat covered the soil surface (Bolhuis et al. 2013). In 2014, the average annual temperature was $11.5^{\circ} \mathrm{C}$, with a measured summer maximum of $34.4^{\circ} \mathrm{C}$. There were 8 days in 2014 on which the temperature exceeded $25.0^{\circ} \mathrm{C}$, and an additional 67 days with temperatures exceeding $20.0^{\circ} \mathrm{C}$. Annual precipitation was $621.8 \mathrm{~mm}$, making 2014 a warmer and dryer year compared to long term averages (all climate data from weather station 'Lauwersoog', The Netherlands. Source: http://cdn.knmi.nl/knmi/map/page/klimatologie/gegevens/ mow/jow_2014.pdf).

\section{Artificial heat waves in the field}

We established four spatially separated plots which were aligned parallel to the dune ridge and the sea. Plots were chosen to have similar elevation above mean sea level and, therefore, comparable inundation regimes and vegetation types (Fig. S1). The distance between plots ranged from $\sim 15$ to $\sim 80 \mathrm{~m}$ to reduce spatial variability over larger scales. Within these four plots, four subplots of $70 \times 70 \mathrm{~cm}$ each were created, resulting in a total of 16 subplots. Our experimental capacity was limited to four heating units; therefore, the experiments were carried out in two periods (period 1 from the 3 rd to the 10th of June 2014 and period 2 from the 20th of July to the 7th of August 2014). For each plot the four subplots were randomly assigned to a combination of period and treatment (control period 1 , treatment period 1 , control period 2 , treatment period 2).
To heat the soil in the treated subplots, we covered them with miniature greenhouses (hereafter tents) made out of transparent polythene sheets (Botanico PNI1101) (Fig. S1). Sheets were placed over two crossed plastic pipes $(\varnothing 1 \mathrm{~cm})$ of $\sim 157 \mathrm{~cm}$ length that formed two halve-circle arcs with a maximum height of $50 \mathrm{~cm}$ above the soil. Two ceramic heat emitters (60 Watts each, RepTech) were attached on the pipes, each $12.5 \mathrm{~cm}$ from the center were the pipes crossed. Heat emitters were placed $20 \mathrm{~cm}$ above the soil surface and were powered to their full capacity by a generator (Honda EU10i). Tents were set-up for 4 h between $\sim$ 11:00 and 15:00 to specifically mimic an increase in maximum temperature during the hottest period of each day. Using this method, the treatment subplots were warmed relative to the control subplots, even though absolute temperatures reached were dependent on the ambient conditions. During heating, the base of the tents were pressed to the ground by placing a heavy iron chain on top of a 3-5 cm wide band of sheet around the subplots, to limit movement of animals out of the plots. The tents remained on the subplots for an additional hour with the heat emitters turned off to allow the air to cool down gradually. Control subplots were not covered by tents and exposed to ambient field conditions. Compared to the control subplots, the heating resulted in an average increase of the maximum temperature of $7.4^{\circ} \mathrm{C}$ for period 1 and $4.0^{\circ} \mathrm{C}$ for period 2 (Table 2 and Fig. S5).

Since the tents were removed daily, temperatures dropped to ambient night temperatures, whereas during natural heat waves it is not uncommon that also night temperatures are relatively high. However, nighttime exposure was not included in this experiment as it could have introduced unwanted artefacts such as a high relative humidity. By removing the tents, animals possibly moved in or out of the subplots during the night, potentially diluting the effect of heating. However, soil organisms generally have a small home range, as was the case for our species. More specifically, the genus of the most abundant prey species in our study, Isotoma (Collembola) moves only $\sim 5 \mathrm{~cm} \mathrm{week}^{-1}$ (Ojala and Huhta 2001), and the most abundant predator species, i.e., web building dwarf spiders (Linyphiidae), can be considered largely sedentary. Lycosid spiders were the most mobile species, but mark-recapture studies shows only $\sim 20 \%$ probability to move to an adjacent plot $(1 \mathrm{~m})$ in 4 days (Ahrens and Kraus 2006).

Temperature was recorded to the nearest $0.01{ }^{\circ} \mathrm{C}$ every minute using temperature loggers (Tinytag Plus2) of which the sensors were placed horizontally on the soil surface in both control and heated subplots. Temperature profiles were retrieved with the program EasyView (Version 5.7.0.1. (C) INTAB Interface-Teknik AB 2002) and data were exported to Microsoft Excel (Microsoft Office 365 version 1611) for further analysis. Every day, the average and maximum temperature was calculated for both the control and heated 
subplots of a selected plot pair. Per subplot, the average of the temperature data of the exposure days was used for statistical analysis. A paired $t$ test was performed in Microsoft Excel to test for effectiveness of the heat treatment.

In the first experimental period we applied a single heat wave of 5 consecutive days, which resembles a meteorological heat wave according to The Royal Netherlands Meteorological Institute (https://www.knmi.nl/kennis-endatacentrum/uitleg/hittegolf, in Dutch). We used a staggered exposure period, starting with the exposure of one pair of subplots (control and treatment), and adding one random pair to the exposure every day. This design allowed us to harvest a single pair of subplots per day (which was necessary due to logistic constraints, see below), while each pair still had 5 days of exposure. Preliminary analysis showed no effect of this single heat wave on the thermal sensitivity of the soil organisms. Therefore, in the second experimental period we applied two consecutive artificial heat waves of 5 days each to further increase thermal stress. We are aware that this experimental design does not allow us to disentangle effects of the experimental period and number of heat waves, therefore the combined effect of experimental period and number of heat waves was included as a random effect in the statistical analyses to account for any introduced variation by these combined effects (see Supplemental information 2). In total, this design resulted in eight heated and eight control subplots for the full experimental period.

\section{Critical thermal maximum ( $\left.\mathrm{CT}_{\max }\right)$}

To obtain samples for the measurement of $\mathrm{CT}_{\max }$, animals were collected from the control and heated subplots directly after the removal of the tents. Vegetation and top soil in the subplots was carefully, manually searched for $1 \mathrm{~h}$. The arthropods (i.e., springtails, spiders and insects) were collected alive using a pooter and stored in plastic containers ( $13.1 \mathrm{~cm}$, height $5.8 \mathrm{~cm}$ ) with a $\sim 0.5 \mathrm{~cm}$ thick bottom of water-saturated plaster of Paris and some vegetation material. Predators were collected in separate containers from the prey to prevent predation. The containers were transported to the laboratory within an hour.

For the measurement of $\mathrm{CT}_{\max }$ animals were placed individually in a glass jar $(\varnothing 2.7 \times 7.5 \mathrm{~cm})$ with a $\sim 2.1 \mathrm{~cm}$ layer of water-saturated pink plaster of Paris (Regal Die Violet class 4, Gips Zwolman) to prevent dehydration. Twenty-five jars were placed in a Styrofoam plate $(37.5 \times 29.9 \times 2.0 \mathrm{~cm})$ in a $5 \times 5$ grid with $\sim 2.3 \mathrm{~cm}$ intervals. This plate was placed in a $19 \mathrm{~L}$ water bath (Julabo Bath tank 19) with a heating immersion circulator (Julabo MB) (Fig. S3). The water level in the bath was set to come up to the first $0.5 \mathrm{~cm}$ of the Styrofoam plate. The bottom of the vials protruded $\sim 2.1 \mathrm{~cm}$ from the underside of the Styrofoam plate to facilitate heat conduction from the water to the layer of plaster in the jar.
Animals from different treatments or size classes were always mixed within a single run, to prevent bias between runs, and were randomly assigned to the 24 jars. Three runs per pair of control and heated subplots were needed to test the collected animals for $\mathrm{CT}_{\max }$, resulting in measurements of a maximum of 72 individual animals per day. The water was heated following a ramping assay from an initial temperature of $20^{\circ} \mathrm{C}$, with a steady increase of $0.35{ }^{\circ} \mathrm{C} \mathrm{min}-1$ (Julabo EasyTemp software version 3.4.1). The initial temperature of $20^{\circ} \mathrm{C}$ was close to the soil temperatures at time of sampling, and chosen to standardize measurements over the different days. During each run a logger (iButton, Maxim Integrated DS1923) was placed in the center jar of the plate to monitor changes in moisture and temperature. The programmed increase of $0.35^{\circ} \mathrm{C} \mathrm{min}^{-1}$ of the water resulted in a $0.33{ }^{\circ} \mathrm{C} \mathrm{min}{ }^{-1}$ steady increase within the test vials. This rate was relatively fast compared to other studies, which are typically in the range of $0.06-0.25{ }^{\circ} \mathrm{C} \mathrm{min}^{-1}$ (Terblanche et al. 2007; Moretti et al. 2017), but this rate was chosen to complete three water bath runs per day, which was essential to process all animals per subplot pair within a day. $\mathrm{CT}_{\max }$ values are known to depend on methodological context (e.g., Terblanche et al. 2007; Chown et al. 2009; Mitchell and Hoffmann 2010), with higher ramping rates giving rise to higher estimates of $\mathrm{CT}_{\max }$ (because of shorter total exposure time until death). Although the absolute value of $\mathrm{CT}_{\max }$ measured for each individual in our study may partly result from the chosen ramping rate, differences between individuals or species were meaningful because the same methodology was applied throughout the experiment. A correction was applied to correct the recorded water temperature to the air temperature in the vials (Fig. S4).

Animals in the vials were observed continuously during the gradual increase of the air temperature. $\mathrm{CT}_{\max }$ was recorded as the temperature at which there was no movement of appendages of the animal observable after gently touching them with a fine brush. We chose this protocol to standardize the method for use of a diversity of taxa within one measurement (for a discussion on possible endpoints in $\mathrm{CT}_{\max }$ measurements see Lutterschmidt and Hutchison 1997).

After the $\mathrm{CT}_{\max }$ measurements, the animals were fixed in $70 \%$ ethanol and stored for species identification and body size measurements. For body size measurements we used a mounted camera (Olympus SC30) on a Leica Wild M8 stereomicroscope (with $6 \times$ magnification) to make digital images of each individual. During measurement, the animals remained submerged in $70 \%$ ethanol. Body size was measured from these images using cellSens Entry 1.7 software (Olympus). Collembola were measured dorsolaterally, following and including the curvature that normally occurs when storing some Collembola in ethanol. Hemiptera, Coleoptera and Araneae do not show this altered body shape and were measured dorsally, to the nearest $\mu \mathrm{m}$. For 
spiders it is also common to use the length or width of the cephalothorax, but we refrained from using these measurements to be able to directly compare the body sizes of all taxonomic groups.

\section{Analysis and statistics}

Statistical analyses were performed using $\mathrm{R}$ version 3.3.1 (R Core Team 2016), which was run in the RStudio interface (RStudio Team 2015). Species with fewer than three individuals were not included in any of the analyses. We ran linear mixed effects models on the $\mathrm{CT}_{\max }$ data using the package "Ime4" (Bates et al. 2015) with the random factors: plot (spatial difference between the plots, linking the subplot pairs), experiment (experimental heating period 1 vs period 2) and run (temporal variation between water bath runs within a pair of subplots). To test whether the fit of the statistical models was improved when including interactions between the main factors, or to test if a main factor improved the model fit, we obtained Wald Chi-square statistics from the "Anova" function in the statistical package "Car" (Fox and Weisberg 2011).

First, we tested whether life stage and sex had significant effects on the observed $\mathrm{CT}_{\max }$ values. The effect of life stage could only be assessed in the bug family Saldidae. Being hemimetabolous, both nymphs and adults live on the soil surface, and hence have comparable thermal environments throughout their life history. This does not hold for the holometabolous beetle family Heteroceridae, where a large part of the larval development takes place belowground. Also the spiders were not suitable for testing for life stage-related changes in $\mathrm{CT}_{\max }$, since juvenile spiders could not be identified to the species level. Effect of sex on the observed $\mathrm{CT}_{\max }$ was tested for the spiders Erigone longipalpis and Oedothorax retusus. The absence of a significant effect of the factors of life stage and sex would justify their omissions from further analysis.

We then tested whether the heating treatment and taxonomic group had a significant influence on the measured $\mathrm{CT}_{\max }$ values, and whether this effect differed between taxa (Treatment $\times$ Taxon). Only the taxonomic groups for which we had data on more than ten individuals in the treatment and control subplots were included. Contrasts analysis was performed on significant fixed factors using the function "Ismeans" in the similarly named package (Lenth 2016), with a Tukey correction for multiple comparisons. To test for interspecific effects of body size on the observed $\mathrm{CT}_{\max }$ values, we fitted a weighted least squares linear model to the average $\mathrm{CT}_{\max }$ and average body size of all taxonomic groups, with the weight being the number of measured individuals per group. Besides this interspecific relationship between $\mathrm{CT}_{\max }$ and body size, it is expected that variation within taxa might contribute to the intraspecific variation in $\mathrm{CT}_{\max }$. We used the data of the taxonomic groups with more than ten measured individuals to fit a linear mixed effects model with taxonomic group, individual body size and their interaction (Taxon $\times$ Body size), to test their effect on $\mathrm{CT}_{\max }$. When interactions between taxonomic group and body size were significant, we investigated this intraspecific pattern for each taxon. Assumptions of the applied tests were visually checked by plotting the residuals of the fitted models.

\section{Results}

\section{Soil fauna community}

In total, we measured the $\mathrm{CT}_{\max }$ and body size of 552 individuals of the arthropod community living on the soil surface (Table 1). The most abundant taxonomic group was the
Table 1 An overview of the soil animals for which $\mathrm{CT}_{\max }$ and body size were measured and included in the analysis

\begin{tabular}{llllrr}
\hline Species & Author & Taxon & Family & \multicolumn{2}{c}{$N$} \\
\cline { 4 - 6 } & & & & Control & Treatment \\
\hline Isotoma riparia & (Nicolet 1842) & Collembola & Isotomidae & 127 & 128 \\
Walckenaeria kochi & (O.P.-Cambridge 1872) & Araneae & Linyphiidae & 3 & 0 \\
Oedothorax retusus & (Westring 1851) & Araneae & Linyphiidae & 20 & 37 \\
Erigone longipalpis & $($ Sundevall 1830) & Araneae & Linyphiidae & 15 & 21 \\
Linyphiidae (juvenile) & & Araneae & Linyphiidae & 41 & 38 \\
Pachygnatha degeeri & Sundevall 1830 & Araneae & Tetragnathidae & 3 & 1 \\
Argenna patula & $($ Simon 1874) & Araneae & Dictynidae & 2 & 4 \\
Lycosidae (juvenile) $)^{\text {a }}$ & & Araneae & Lycosidae & 16 & 15 \\
Saldidae & & Hemiptera & Saldidae & 14 & 17 \\
Heterocerus sp. & & Coleoptera & Heteroceridae & 10 & 10 \\
& & & & 251 & 271 \\
\hline
\end{tabular}

$N$ gives the number of individuals included in the analysis

${ }^{a}$ Combination of Pardosa purbeckensis F. O. Pickard-Cambridge, 1895 and Pirata piraticus (Clerck 1757) 
Collembola, present with a single species Isotoma riparia $(N=255)$. Two Linyphid spider species were present in high numbers, i.e., Erigone longipalpis $(N=36)$ and Oedothorax retusus $(N=57)$. Juvenile Linyphiidae could not be determined to species level and were pooled together $(N=79)$. The Lycosidae were also abundant, but we caught mostly juveniles $(N=31)$ and only two adults. As the adults belonged to two different species of wolf spiders, they were excluded from further analysis. We also found several spider species with lower numbers of adults, i.e., Walckenaeria kochi $(N=3)$, Argenna patula $(N=6)$ and Pachygnatha degeeri $(N=4)$. Finally, two insect taxa were found: Heterocerus sp. (Coleoptera, $N=20$ ) and Saldidae (Hemiptera, $N=31)$.

Statistical analysis showed that the heating treatment had a significant effect on both the average and maximum temperatures in both treatment periods (Table 2, Fig. S5).

\section{No effects of life stage and sex on $\mathrm{CT}_{\max }$}

The effect of life stage on $\mathrm{CT}_{\max }$ was tested in the Saldidae. Our analysis of $\mathrm{CT}_{\max }$ shows that including life stage did not significantly improve the fit of the model $\left(\chi_{(1)}^{2}=0.035\right.$, $P=0.85$, Fig. S6a).

Sexual dimorphism is a second factor that could potentially increase intraspecific variation in $\mathrm{CT}_{\max }$ for some of the taxonomic groups. Of the two Linyphiidae species tested, $O$. retusus $(N=57)$ showed clear body size dimorphism, with larger females than males, whereas E. longipalpis $(N=36)$ did not show size dimorphism. However, the statistical models showed no significant effects of sex on $\mathrm{CT}_{\max }$ for either of these species $\left(O\right.$. retusus: $\left(\chi_{(1)}^{2}=0.43\right.$,
$P=0.51) ;$ E. longipalpis: $\left(\chi_{(1)}^{2}=2.7314, P=0.098\right)$, see also Fig S6b, c. Based on the lack of significance of life stage and sex in the tested species, these variables were not included in the remainder of the analyses.

\section{The effect of artificial heat waves on $\mathrm{CT}_{\max }$}

Seven taxonomic groups had a sufficiently large sample size (i.e., $N>10$ in both treatment and control) to test our hypothesis that exposure to higher temperatures in the field will result in higher $\mathrm{CT}_{\max }$ values. We found that there was no interaction between the two main effects Taxon and Treatment $\left(\chi_{(6)}^{2}=4.0, P=0.68\right)$. Moreover, only Taxon had a strong effect on the observed $\mathrm{CT}_{\max }$ values $\left(\chi_{(6)}^{2}=962.8\right.$, $P<0.001)$, and the heating treatments did not have an effect on the $\mathrm{CT}_{\max }$ values $\left(\chi_{(1)}^{2}=0.60, P=0.44\right)$.

As the heating treatments did not influence $\mathrm{CT}_{\max }$ values, we ran the model again without treatment, this time including all available taxa. Taxonomic group remained highly significant in this analysis $\left(\chi_{(9)}^{2}=1051.6, P<0.001\right)$, and contrast analysis revealed large differences in $\mathrm{CT}_{\max }$ between the taxonomic groups (Fig. 1). Especially the main prey species of our arthropod community, I. riparia $\left(\mathrm{CT}_{\max }=43.4 \pm 1.8^{\circ} \mathrm{C}\right)$ had a significantly lower heat tolerance than its most abundant predators, $O$. retusus $\left(\mathrm{CT}_{\max }=45.6 \pm 1.8^{\circ} \mathrm{C} ; t\right.$ ratio $\left.=7.5 ; P<0.001\right)$, E. longipalpis $\left(\mathrm{CT}_{\max }=47.1 \pm 2.2{ }^{\circ} \mathrm{C} ; t\right.$ ratio $\left.=12.7 ; P<0.001\right)$, juvenile Linyphiidae $\left(\mathrm{CT}_{\max }=46.1 \pm 1.9 ; t\right.$ ratio $=10.5$; $P<0.001)$ and the juvenile Lycosidae
Table 2 Abiotic conditions in control versus heated subplots

\begin{tabular}{lcc}
\hline Experiment & Average temp. $\left({ }^{\circ} \mathrm{C} \pm \mathrm{SD}\right)$ & Max. temp. $\left({ }^{\circ} \mathrm{C} \pm \mathrm{SD}\right)$ \\
\hline Period 1: one heat wave & & \\
Control & $26.1 \pm 1.6$ & $31.1 \pm 1.5$ \\
Treatment & $32.7 \pm 1.4^{* *}$ & $38.5 \pm 1.1^{* *}$ \\
Difference & $6.6 \pm 1.3$ & $7.4 \pm 1.9$ \\
Period 2: Two consecutive heat waves & & \\
Heat wave 1 & & \\
Control & $29.6 \pm 0.7$ & $32.2 \pm 0.7$ \\
Treatment & $33.1 \pm 0.5^{* * *}$ & $36.4 \pm 0.4^{* * *}$ \\
Difference & $3.5 \pm 0.3$ & $4.2 \pm 0.4$ \\
Heat wave 2 & & \\
Control & $30.1 \pm 0.7$ & $34.6 \pm 0.7$ \\
Treatment & $33.6 \pm 0.9^{* * *}$ & $38.3 \pm 0.8^{* * *}$ \\
Difference & $3.5 \pm 0.2$ & $3.7 \pm 0.3$ \\
\hline
\end{tabular}

Temperature was recorded at the soil surface. Values were averaged over the 5 days of exposure per plot, which masks part of the variation of the actual daily differences in the field

$* P<0.05, * * P<0.01, * * * P<0.001$, paired $t$ test (See Fig. S5 for details per plot pair) 
Fig. 1 Differences in $\mathrm{CT}_{\max }$ for the taxonomic groups included in our analysis. Boxplots indicate the median with quartiles, with whiskers indicating 1.5 times the interquartile range. In this analysis, data of the control and treatment subplots was combined, as there was no significant effect of the heating treatment on $\mathrm{CT}_{\max }$ of the different taxa. For clarity, the different taxonomic groups are colour coded. Collembola and Heteroceridae are considered decomposers, while all spider species (Araneae) are predators. Saldidae are thought to either actively predate or feed on dead animals. For full species names see Table 1. Different letters indicate statistical difference at $P<0.05$

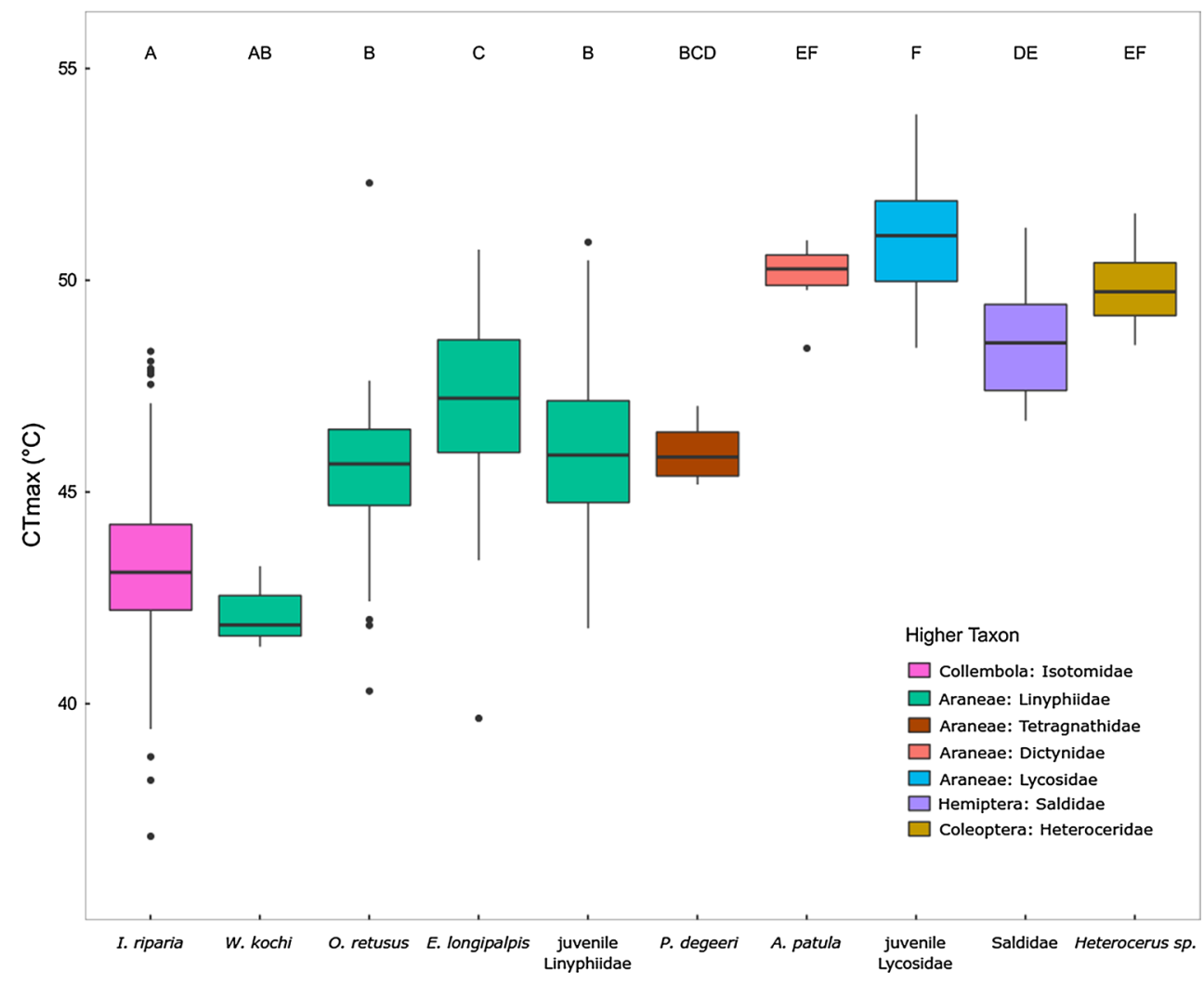

Table 3 Intraspecific variation in $\mathrm{CT}_{\max }$ of the seven taxa with $>10$ individuals in both control and treatment subplots

\begin{tabular}{lllll}
\hline Species & $\begin{array}{l}\text { Mean } \\
\mathrm{CT}_{\max }\end{array}$ & $\begin{array}{l}\text { St. devia- } \\
\text { tion }\end{array}$ & $\begin{array}{l}\text { Range } \\
\text { min-max } \\
\mathrm{CT}_{\max }\end{array}$ & $\begin{array}{l}\text { Total varia- } \\
\text { tion in } \mathrm{CT}_{\max }\end{array}$ \\
\hline $\begin{array}{l}\text { I. riparia } \\
\text { O. retusus }\end{array}$ & 43.4 & 1.8 & $37.0-48.5$ & 11.5 \\
$\begin{array}{l}\text { E. longipal- } \\
\text { pis }\end{array}$ & 47.1 & 2.6 & $39.8-50.9$ & 11.1 \\
$\begin{array}{l}\text { Linyphiidae } \\
\text { (juv) }\end{array}$ & 46.1 & 1.9 & $41.9-51.0$ & 9.1 \\
$\begin{array}{c}\text { Lycosidae } \\
\quad \text { juv) }\end{array}$ & 51.1 & 1.3 & $48.5-54.0$ & 5.5 \\
$\begin{array}{l}\text { Saldidae } \\
\begin{array}{l}\text { Heterocerus } \\
\text { sp. }\end{array}\end{array}$ & 58.6 & 1.3 & $46.8-51.4$ & 4.6 \\
\hline
\end{tabular}

Full species names are given in Table 1

$\left(\mathrm{CT}_{\max }=51.1 \pm 1.3^{\circ} \mathrm{C} ; t\right.$ ratio $=22.8 ; P<0.001 ;$ See Fig. 1 and Table 3 for details on the other taxa).

\section{Inter- and intraspecific variation in $\mathrm{CT}_{\max }$ and the effect of body size}

To test if the observed interspecific differences in $\mathrm{CT}_{\text {max }}$ were related to variation in species' body size, a linear model was fitted with average $\mathrm{CT}_{\max }$ and average body size per taxonomic group, each weighted for the number of observations in that taxon. There was no significant relationship between average body size and average $\mathrm{CT}_{\max }$ value of the taxa $\left(t_{(1,8)}=1.58 ; P=0.153\right)$ (Fig. S7).

Besides interspecific variation, we also observed that $\mathrm{CT}_{\max }$ varied considerably within each taxon. For example, $\mathrm{CT}_{\max }$ of I. riparia ranged from 37.0 to $48.5{ }^{\circ} \mathrm{C}$ and the total variation in $O$. retusus was even higher: ranging from 40.4 to $52.4{ }^{\circ} \mathrm{C}$ (see Table 3 for all taxa). We tested intraspecific variation in body size as an explanatory variable for intraspecific variation of $\mathrm{CT}_{\max }$ values. In addition to taxonomic group $\left(\chi_{(6)}^{2}=942.4, P<0.001\right)$, intraspecific variation in body size was also highly significant with an overall negative correlation between individual body size and $\mathrm{CT}_{\max }\left(\chi_{(1)}^{2}=12.6, P<0.001\right)$. However, there was a significant interaction between the factors taxon and body size $\left(\chi_{(9)}^{2}=22.4, P=0.001\right)$, indicating that the effect of body size on $\mathrm{CT}_{\max }$ differed between taxonomic groups.

This interaction was further investigated by separately analysing the effect of individual body size on $\mathrm{CT}_{\max }$ for seven taxa with sufficient sample sizes (the same taxa as used to test for artificial heating above, Table 4). We found that $I$. riparia and Heterocerus sp. had a significant negative relationship between $\mathrm{CT}_{\max }$ and body size $\left(\chi_{(1)}^{2}=17.3\right.$, 
Table 4 Results of the Wald Chi-square tests body size as the main effect in the fitted linear mixed effect models

\begin{tabular}{|c|c|c|c|c|c|}
\hline $\mathrm{CT}_{\max }(\operatorname{taxon}) \sim$ & Fixed and random factors & $\chi^{2}$ & $D f$ & $P$ & Slope \\
\hline I. riparia & Body size $+(1 \mid$ Experiment $)+(1 \mid$ Run $)+(1 \mid$ Plot $)$ & 17.30 & 1 & $<0.001$ & -0.82 \\
\hline O. retusus & Body size $+(1 \mid$ Experiment $)+(1 \mid$ Run $)+(1 \mid$ Plot $)$ & 0.25 & 1 & 0.615 & -0.29 \\
\hline E. longipalpis & Body size $+(1 \mid$ Run $)+(1 \mid$ Plot $)$ & 0.43 & 1 & 0.513 & -0.92 \\
\hline Linyphiidae (juv) & Body size $+(1 \mid$ Experiment $)+(1 \mid$ Run $)+(1 \mid$ Plot $)$ & 4.63 & 1 & 0.032 & 1.09 \\
\hline Lycosidae (juv) & Body size $+(1 \mid$ Experiment $)+(1 \mid$ Run $)+(1 \mid$ Plot $)$ & 0.45 & 1 & 0.501 & 0.19 \\
\hline Saldidae & Body size $+(1 \mid$ Experiment $)+(1 \mid$ Run $)+(1 \mid$ Plot $)$ & 0.57 & 1 & 0.450 & 0.22 \\
\hline Heterocerus sp. & Body size $+(1 \mid$ Run $)+(1 \mid$ Plot $)$ & 9.49 & 1 & 0.002 & -0.92 \\
\hline
\end{tabular}

The effect of body size on $\mathrm{CT}_{\max }$ was tested for these seven taxa separately. Taxa for which $\mathrm{CT}_{\max }$ was influenced by body size are displayed in bold. Full species names are given in Table 1
$P<0.001$ and $\chi_{(1)}^{2}=9.5, P=0.002$ for $I$. riparia and

Heterocerus sp., respectively). For every additional $\mathrm{mm}$ in body size, the $\mathrm{CT}_{\max }$ was reduced by 0.82 and $0.92^{\circ} \mathrm{C}$ for I. riparia and Heterocerus sp., respectively. Especially for I. riparia these values are substantial as body sizes ranged from $\sim 1.2$ to $\sim 4.5 \mathrm{~mm}$, resulting in a difference in thermal tolerance of almost $3{ }^{\circ} \mathrm{C}$ from the smallest to largest individuals. On contrary, the juvenile Linyphiidae showed a positive relationship between $\mathrm{CT}_{\max }$ and body size $\left(\chi_{(1)}^{2}=4.63, P=0.032\right)$. This results in a $1.09{ }^{\circ} \mathrm{C}$ increase in $\mathrm{CT}_{\max }$ for every additional $\mathrm{mm}$ of length.

\section{Discussion}

In this study we investigated inter- and intraspecific differences in heat tolerance among species of a soil arthropod community exposed to artificial heat waves. We found strong interspecific differences in heat tolerance, with the dominant Collembola species being more sensitive to high temperatures than its predators, mostly spider species (Fig. 1). Additionally, we observed large intraspecific variation in heat tolerance (Table 3), partly related to body size. Artificial heating of communities in the field, mimicking naturally occurring heat waves, had no detectable effect on heat tolerance of individual species. We discuss the ecological implications of inter- and intraspecific variation in heat tolerance on species interactions.

\section{Interspecific differences in heat tolerance}

We observed significant differences in the level of heat tolerance between taxonomic groups. The prey species I. riparia had a significantly lower $\mathrm{CT}_{\max }$ than most of its predator species, and also among predator species heat tolerance differed significantly. For example, within the spiders, the Lycosidae and Dictynidae had significantly higher $\mathrm{CT}_{\max }$ values than the Linyphiidae and Tetragnathidae. Although interspecific differences in $\mathrm{CT}_{\text {max }}$ between taxa have been reported before (e.g., Addo-Bediako et al. 2000; Sunday et al. 2011; Araújo et al. 2013), this— to our knowledge—has never been reported for interacting species in a terrestrial community under field conditions. The information obtained from this approach therefore adds to studies focusing on specific interactions in the community (Sentis et al. 2013; Puentes et al. 2015) or studies comparing heat tolerances across spatial scales (e.g., Deutsch et al. 2008; Araújo et al. 2013).

The mechanisms underlying these interspecific differences in thermal tolerance are largely unknown. Previous research has already pointed to evolutionary constraints at the upper thermal limits of species (Addo-Bediako et al. 2000; Chown 2001; Mitchell et al. 2011; Kellermann et al. 2012; Hoffmann et al. 2013). However, a mechanistic explanation as to which trait is underlying these constraints is not evident and multiple factors can be simultaneously at play, such as membrane lipid composition (van Dooremalen et al. 2013), innate differences in heat shock protein expression (Belén Arias et al. 2011), oxygen limitation at higher temperatures (Klok et al. 2004), and interspecific differences in body size. Specifically the difference in body size is interesting considering that on the soil surface, which is heated by solar radiation, the smaller species in this community may experience higher temperatures compared to larger species because the smaller species' bodies are closer to the heated soil surface (e.g., Kaspari et al. 2015). However, we found no significant relation between the average $\mathrm{CT}_{\max }$ and body size of the taxa investigated here (Fig. S7). Measurements of both heat tolerance and these underlying traits in combination with phylogenetic analysis could potentially provide additional answers, but to do so more data are needed that are collected in a standardized and comparative way (Moretti et al. 2017).

The finding of substantial interspecific differences in heat tolerance within a single community, raises the question how these differences affect the dynamics of species interactions during and after heat waves. This is especially relevant as it is known that altered species interactions can pose a larger effect on communities than the direct abiotic effects (Ockendon et al. 2014). In line with the thermal mismatch 
hypothesis postulated for host-parasite interactions (Nowakowski et al. 2016; Cohen et al. 2017; Greenspan et al. 2017), our results indicate that thermal mismatches might also occur in predator-prey interactions in a community. Species with a high thermal tolerance are expected to be less affected by hot weather extremes than species with low thermal tolerance. Therefore, when such species co-occur, the species within communities will most likely not respond to climate change in similar ways (Petchey et al. 1999; Voigt et al. 2003).

The fact that higher trophic levels in our study seem to be more tolerant to high temperatures also highlights the difference in climate change effects of short term extreme events compared to more gradual and longer lasting time scales, as studies on the latter usually find that higher trophic levels are more sensitive to increases in temperature than lower trophic levels (e.g., Petchey et al. 1999; Voigt et al. 2003; Vasseur and McCann 2005; Gilman et al. 2010). This difference can be explained by our focus on the direct, physiological differences between the taxa, which is especially relevant when communities are exposed to extreme events. As such extremes can occur for one or several days (such as the 5 days used here), the stress is sudden and can directly cause differences in survival between species when their physiological thresholds are surpassed. On the contrary, the studies quoted above focus on longer time scales (even spanning multiple generation), and therefore on consequences for population dynamics. This emphasizes that the specific form of temperature changes that global warming can bring about (e.g., extreme event versus gradual change), can yield different predictions on the outcome at the community level.

\section{Intraspecific variation of thermal tolerance}

In addition to interspecific differences in heat tolerance, within-species variation can also affect the outcome of species interactions. When intraspecific variation is large, some proportion of the individuals could survive and continue to interact in the community, depending on the severity of the heat wave. We found considerable levels of intraspecific variation in $\mathrm{CT}_{\max }$ values of the prey species I. riparia $\left(37.0-48.5^{\circ} \mathrm{C}\right.$ ) and in some of the other taxa (see Fig. 1 and Table 3), with some of the individuals of interacting species showing overlap in tolerance trait values. Part of this intraspecific variation of $\mathrm{CT}_{\max }$ may have resulted from variation in body size within taxa. We found a negative relationship of body size with $\mathrm{CT}_{\max }$ in adult Heteroceridae and I. riparia $\left(\sim 1^{\circ} \mathrm{C}\right.$ lower for every $0.9 \mathrm{~mm}$ extra length). The degree of intraspecific variation of heat tolerance observed in our study is comparable to what is reported in existing literature, (e.g., Terblanche et al. 2005; Jumbam et al. 2008; Chown et al. 2009; Mitchell and Hoffmann 2010, when standard deviations are recalculated from reported standard errors). As we measured individuals straight from the field, without an acclimation period in the laboratory, we were able to obtain a nearly "complete estimation of within-species trait distribution" (sensu Violle et al. 2012) from the measured individuals in our community. We argue that to make statements on the effects of temperature on species performance and species interactions in natural ecosystems, heat tolerance should be measured directly from the field and encompass all relevant life stages of the species to prevent underestimation of trait variation. This is especially true when the intraspecific variation is important in understanding effects of climatic extremes on species interactions.

\section{No evidence for heat wave induced phenotypic plasticity of $\mathrm{CT}_{\text {max }}$}

Phenotypic plasticity is a common way to mediate sudden adverse effects of changing environmental pressures (DeWitt and Scheiner 2004; Chown et al. 2007) and can be of particular importance when considering species interactions (Berg and Ellers 2010). Despite the highly dynamic character of the thermal regime at our field site, which is generally thought to favour phenotypic plasticity of the related traits (Agrawal 2001), we found no effects of the heating treatment on $\mathrm{CT}_{\max }$ in any of the studied taxonomic groups. Such a result is inconsistent with a scenario of phenotypic plasticity of $\mathrm{CT}_{\max }$. Previous studies have reported that plastic responses in traits related to thermal maxima are often less pronounced than those of thermal minima (e.g., Chown 2001; Jumbam et al. 2008; Alford et al. 2012; van Heerwaarden et al. 2016; see also the recent review on plasticity in extreme environments by Chevin and Hoffmann 2017), indicating that this limited plasticity of thermal maxima might be a general phenomenon among arthropods.

Animals can also behaviourally respond to changes in temperature to avoid adverse conditions (e.g., Kearney et al. 2009; Buckley et al. 2015; Duffy et al. 2015; Woods et al. 2015; MacLean et al. 2016). Horizontal or vertical movement in the soil allows animals to utilize small-scale spatial variability in micro-habitat thermal conditions. Even small absolute differences in temperatures between micro-habitat patches can be ecologically significant by reducing or increasing temperature by the few degrees that may determine survival or death (Scheffers et al. 2014; Kaspari et al. 2015; Pincebourde and Casas 2015). For instance, dense tussocks can reduce the amplitude of temperature fluctuations by several degrees, as we observed in our field site (Fig. S8), and hiding in this buffered microhabitat might prevent exposure of individuals to lethal high temperatures (Huey et al. 2012). To prevent variation caused by differences in microhabitats, we choose our plots to have homogeneous vegetation without such dense tussocks. A similar reduction in exposure to 
high temperatures may be achieved by vertical movement deeper into the soil (e.g., van Dooremalen et al. 2013). Although temperature differences down the soil profile can be large even over a few centimetres (Krab et al. 2015), we do not expect that our study organisms can fully utilize this temperature gradient. The vegetated beach ecosystem we studied has only limited possibilities for vertical stratification as the sandy soil is rather compact and often water locked. So both phenotypic and behavioural plasticity likely play a limited role in the patterns observed in our study.

In this study, we directly compared temperature sensitivity across trophic levels in a local terrestrial community. We observed interspecific differences in heat tolerance within a soil arthropod community, especially between the more temperature sensitive prey I. riparia (Collembola) and their more tolerant predators. As a consequence, during a heat wave the population size of prey might be reduced and negatively affect the growth rate or abundance of the predators, causing bottom-up effects in this food web. A severe reduction in Collembola availability could potentially also lead to a switch to a different prey species, including the possibility of intra-guild predation or cannibalism (Samu et al. 1999), and an associated change in community structure (Barton and Schmitz 2009; Rosenblatt and Schmitz 2016). In this study we focused specifically on a trait related to the effects of extreme temperatures, the Critical Thermal maximum $\left(\mathrm{CT}_{\max }\right)$. We argue that applying a trait-based approach allows for the formulation of predictions on how trophic interactions in food webs will be affected by extreme climatic events (sensu McGill et al. 2006; Violle et al. 2007). Including ecophysiological trait measurements, such as heat tolerance, in field studies on effects of climate extremes on community composition can therefore be a powerful method to point out direct effects of abiotic change at the species level, but can also help to reveal physiological mismatches between interacting species, which might shape the community dynamics on longer time scales.

Acknowledgements We would like to thank the journal editors and three anonymous reviewers for their useful comments on an earlier version of this manuscript. We would also like to thank Herman A. Verhoef for constructive discussions at the initial stages of planning the experiment and Jasper Molleman and Kiki Kersten for providing the calibration curve used to calculate $\mathrm{CT}_{\max }$ values from the water bath temperature. This study was financed by NWO Grant 821.01.015.

Author contribution statement $\mathrm{OF}$, JE and MB conceived the ideas and designed the methodology; $\mathrm{OF}$ and $\mathrm{MH}$ performed the field experiments; all authors contributed to the collection of the data; OF analyzed the data; OF provided a first draft of the manuscript, which was improved by all authors. All authors gave final approval for publication.
Open Access This article is distributed under the terms of the Creative Commons Attribution 4.0 International License (http://creativecommons.org/licenses/by/4.0/), which permits unrestricted use, distribution, and reproduction in any medium, provided you give appropriate credit to the original author(s) and the source, provide a link to the Creative Commons license, and indicate if changes were made.

\section{References}

Addo-Bediako A, Chown SL, Gaston KJ (2000) Thermal tolerance, climatic variability and latitude. Proc R Soc B 267:739-745. https://doi.org/10.1098/rspb.2000.1065

Agrawal AA (2001) Phenotypic plasticity in the interactions and evolution of species. Science 294:321-326. https://doi.org/10.1126/ science. 1060701

Ahrens L, Kraus JM (2006) Wolf spider (Araneae, Lycosidae) movement along a pond edge. J Arachnol 34:532-539. https://doi. org/10.1636/05-85.1

Albert CH, Grassein F, Schurr FM et al (2011) When and how should intraspecific variability be considered in trait-based plant ecology? Perspect Plant Ecol Evol Syst 13:217-225. https://doi. org/10.1016/j.ppees.2011.04.003

Alford L, Blackburn TM, Bale JS (2012) Effect of latitude and acclimation on the lethal temperatures of the peach-potato aphid Myzus persicae. Agric For Entomol 14:69-79. https://doi. org/10.1111/j.1461-9563.2011.00553.x

Araújo MB, Ferri-Yáñez F, Bozinovic F et al (2013) Heat freezes niche evolution. Ecol Lett 16:1206-1219. https://doi. org/10.1111/ele.12155

Bartlett MK, Zhang Y, Yang J et al (2016) Drought tolerance as a driver of tropical forest assembly: resolving spatial signatures for multiple processes. Ecology 97:503-514. https://doi. org/10.1890/15-0468.1

Barton BT, Schmitz OJ (2009) Experimental warming transforms multiple predator effects in a grassland food web. Ecol Lett 12:1317-1325. https://doi. org/10.1111/j.1461-0248.2009.01386.x

Bates D, Mächler M, Bolker BM, Walker SC (2015) Fitting linear mixed-effects models using lme4. J Stat Softw 67:1-48. https:// doi.org/10.18637/jss.v067.i01

Bateson P, Gluckman P, Hanson M (2014) The biology of developmental plasticity and the predictive adaptive response hypothesis. J Physiol 592:2357-2368. https://doi.org/10.1113/ jphysiol.2014.271460

Belén Arias M, Josefina Poupin M, Lardies MA (2011) Plasticity of life-cycle, physiological thermal traits and Hsp70 gene expression in an insect along the ontogeny: effect of temperature variability. J Therm Biol 36:355-362. https://doi.org/10.1016/j. jtherbio.2011.06.011

Beniston M, Stephenson DB, Christensen OB et al (2007) Future extreme events in European climate: an exploration of regional climate model projections. Clim Chang 81:71-95. https://doi. org/10.1007/s10584-006-9226-Z

Berg MP, Ellers J (2010) Trait plasticity in species interactions: a driving force of community dynamics. Evol Ecol 24:617-629. https://doi.org/10.1007/s10682-009-9347-8

Berg MP, Kiers ET, Driessen G et al (2010) Adapt or disperse: understanding species persistence in a changing world. Glob Chang Biol 16:587-598. https://doi.org/10.1111/j.1365-2486.2009.02014.x

Bokhorst S, Phoenix GK, Bjerke JW et al (2012) Extreme winter warming events more negatively impact small rather than large soil fauna: shift in community composition explained by traits not taxa. Glob Chang Biol 18:1152-1162. https://doi. org/10.1111/j.1365-2486.2011.02565.x 
Bolhuis H, Fillinger L, Stal LJ (2013) Coastal microbial mat diversity along a natural salinity gradient. PLoS One 8:e63166. https://doi.org/10.1371/journal.pone.0063166

Bowler K, Terblanche JS (2008) Insect thermal tolerance: what is the role of ontogeny, ageing and senescence? Biol Rev 83:339-355. https://doi.org/10.1111/j.1469-185X.2008.00046.x

Buckley LB, Ehrenberger JC, Angilletta MJ Jr (2015) Thermoregulatory behaviour limits local adaptation of thermal niches and confers sensitivity to climate change. Funct Ecol 29:1038-1047. https://doi.org/10.1111/1365-2435.12406

Chevin L-M, Hoffmann AA (2017) Evolution of phenotypic plasticity in extreme environments. Philos Trans R Soc B Biol Sci 372:20160138. https://doi.org/10.1098/rstb.2016.0138

Chown SL (2001) Physiological variation in insects: hierarchical levels and implications. J Insect Physiol 47:649-660. https://doi. org/10.1016/S0022-1910(00)00163-3

Chown SL, Slabber S, McGeoch MA et al (2007) Phenotypic plasticity mediates climate change responses among invasive and indigenous arthropods. Proc Biol Sci 274:2531-2537. https://doi. org/10.1098/rspb.2007.0772

Chown SL, Jumbam KR, Sørensen JG, Terblanche JS (2009) Phenotypic variance, plasticity and heritability estimates of critical thermal limits depend on methodological context. Funct Ecol 23:133-140. https://doi.org/10.1111/j.1365-2435.2008.01481.x

Cohen JM, Venesky MD, Sauer EL et al (2017) The thermal mismatch hypothesis explains host susceptibility to an emerging infectious disease. Ecol Lett 20:184-193. https://doi.org/10.1111/ele.12720

De Boeck HJ, Dreesen FE, Janssens IA, Nijs I (2011) Whole-system responses of experimental plant communities to climate extremes imposed in different seasons. New Phytol 189:806-817. https:// doi.org/10.1111/j.1469-8137.2010.03515.x

Deutsch CA, Tewksbury JJ, Huey RB et al (2008) Impacts of climate warming on terrestrial ectotherms across latitude. Proc Natl Acad Sci 105:6668-6672. https://doi.org/10.1073/pnas.0709472105

DeWitt TJ, Scheiner SM (2004) Phenotypic plasticity: functional and conceptual approaches. Oxford University Press, Oxford

Dias ATC, Krab EJ, Mariën J et al (2013) Traits underpinning desiccation resistance explain distribution patterns of terrestrial isopods. Oecologia 172:667-677. https://doi.org/10.1007/ s00442-012-2541-3

Duffy GA, Coetzee BWT, Janion-Scheepers C, Chown SL (2015) Microclimate-based macrophysiology: implications for insects in a warming world. Curr Opin Insect Sci 11:84-89. https://doi. org/10.1016/j.cois.2015.09.013

Easterling DR, Evans JL, Groisman PY et al (2000a) Observed variability and trends in extreme climatic events: a brief review. Bull Am Meteorol Soc 81:417-425. https://doi. org/10.1175/1520-0477(2000)081<0417:OVATIE > 2.3.CO;2

Easterling DR, Meehl Ga, Parmesan C et al (2000b) Climate extremes: observations, modeling, and impacts. Science 289:2068-2074. https://doi.org/10.1126/science.289.5487.2068

Ellers J, Dias ATC, Berg MP (2011) Interaction milieu explains performance of species in simple food webs along an environmental gradient. Open Ecol J 3:12-21. https://doi. org/10.2174/1874213001003040012

Fox J, Weisberg S (2011) An R companion to applied regression, 2nd edn. Sage, Thousand Oaks

Gilman SE, Urban MC, Tewksbury J et al (2010) A framework for community interactions under climate change. Trends Ecol Evol 25:325-331. https://doi.org/10.1016/j.tree.2010.03.002

Greenspan SE, Bower DS, Roznik EA et al (2017) Infection increases vulnerability to climate change via effects on host thermal tolerance. Sci Rep 7:9349. https://doi.org/10.1038/ s41598-017-09950-3

Gutschick VP, BassiriRad H (2003) Extreme events as shaping physiology, ecology, and evolution of plants: toward a unified definition and evaluation of their consequences. New Phytol 160:21-42. https://doi.org/10.1046/j.1469-8137.2003.00866.x

Hoffmann AA (2010) Physiological climatic limits in Drosophila: patterns and implications. J Exp Biol 213:870-880. https://doi. org/10.1242/jeb.037630

Hoffmann AA, Chown SL, Clusella-Trullas S (2013) Upper thermal limits in terrestrial ectotherms: how constrained are they? Funct Ecol 27:934-949. https://doi.org/10.1111/j.1365-2435.2012.02036.x

Huey RB, Kearney MR, Krockenberger A et al (2012) Predicting organismal vulnerability to climate warming: roles of behaviour, physiology and adaptation. Philos Trans R Soc Lond B Biol Sci 367:1665-1679. https://doi.org/10.1098/rstb.2012.0005

Janion C, Worland MR, Chown SL (2009) Assemblage level variation in springtail lower lethal temperature: the role of invasive species on sub-Antarctic Marion Island. Physiol Entomol 34:284-291. https://doi.org/10.1111/j.1365-3032.2009.00689.x

Jentsch A, Kreyling J, Beierkuhnlein C (2007) A new generation of climate change experiments: events, not trends. Front Ecol Environ 5:365-374. https://doi.org/10.1890/1540-9295(2007)5[365:ANG OCE]2.0.CO;2

Jumbam KR, Terblanche JS, Deere JA et al (2008) Critical thermal limits and their responses to acclimation in two sub-Antarctic spiders: Myro kerguelenensis and Prinerigone vagans. Polar Biol 31:215-220. https://doi.org/10.1007/s00300-007-0349-0

Kaspari M, Clay NA, Lucas J et al (2015) Thermal adaptation generates a diversity of thermal limits in a rainforest ant community. Glob Chang Biol 21:1092-1102. https://doi.org/10.1111/gcb.12750

Kayler ZE, De Boeck HJ, Fatichi S et al (2015) Experiments to confront the environmental extremes of climate change. Front Ecol Environ 13:219-225. https://doi.org/10.1890/140174

Kearney M, Shine R, Porter WP (2009) The potential for behavioral thermoregulation to buffer "cold-blooded" animals against climate warming. Proc Natl Acad Sci 106:3835-3840. https://doi. org/10.1073/pnas.0808913106

Kellermann V, Overgaard J, Hoffmann AA et al (2012) Upper thermal limits of Drosophila are linked to species distributions and strongly constrained phylogenetically. Proc Natl Acad Sci USA 109:16228-16233. https://doi.org/10.1073/pnas.1207553109

Kingsolver JG, Woods HA, Buckley LB et al (2011) Complex life cycles and the responses of insects to climate change. Integr Comp Biol 51:719-732. https://doi.org/10.1093/icb/icr015

Klok CJ, Sinclair BJ, Chown SL (2004) Upper thermal tolerance and oxygen limitation in terrestrial arthropods. J Exp Biol 207:23612370. https://doi.org/10.1242/jeb.01023

Krab EJ, Van Schrojenstein Lantman IM, Cornelissen JHC, Berg MP (2013) How extreme is an extreme climatic event to a subarctic peatland springtail community? Soil Biol Biochem 59:16-24. https://doi.org/10.1016/j.soilbio.2012.12.012

Krab EJ, Cornelissen JHC, Berg MP (2015) A simple experimental set-up to disentangle the effects of altered temperature and moisture regimes on soil organisms. Methods Ecol Evol 6:1159-1168. https://doi.org/10.1111/2041-210X.12408

Langlands PR, Brennan KEC, Framenau VW, Main BY (2011) Predicting the post-fire responses of animal assemblages: testing a traitbased approach using spiders. J Anim Ecol 80:558-568. https:// doi.org/10.1111/j.1365-2656.2010.01795.x

Lenth RV (2016) Least-squares means: the R package lsmeans. J Stat Softw 69:1-33. https://doi.org/10.18637/jss.v069.i01

Lindo Z, Whiteley J, Gonzalez A (2012) Traits explain community disassembly and trophic contraction following experimental environmental change. Glob Chang Biol 18:2448-2457. https://doi. org/10.1111/j.1365-2486.2012.02725.x

Lutterschmidt WI, Hutchison VH (1997) The critical thermal maximum: history and critique. Can J Zool 75:1561-1574. https://doi. org/10.1139/z97-783 
MacLean HJ, Higgins JK, Buckley LB, Kingsolver JG (2016) Geographic divergence in upper thermal limits across insect life stages: does behavior matter? Oecologia 181:107-114. https:// doi.org/10.1007/s00442-016-3561-1

McGill BJ, Enquist BJ, Weiher E, Westoby M (2006) Rebuilding community ecology from functional traits. Trends Ecol Evol 21:178185. https://doi.org/10.1016/j.tree.2006.02.002

Mitchell KA, Hoffmann AA (2010) Thermal ramping rate influences evolutionary potential and species differences for upper thermal limits in Drosophila. Funct Ecol 24:694-700. https://doi. org/10.1111/j.1365-2435.2009.01666.x

Mitchell KA, Sgrò CM, Hoffmann AA (2011) Phenotypic plasticity in upper thermal limits is weakly related to Drosophila species distributions. Funct Ecol 25:661-670. https://doi. org/10.1111/j.1365-2435.2010.01821.x

Moretti M, Dias ATC, de Bello F et al (2017) Handbook of protocols for standardized measurement of terrestrial invertebrate functional traits. Funct Ecol 31:558-567. https://doi. org/10.1111/1365-2435.12776

Nakazawa T (2014) Ontogenetic niche shifts matter in community ecology: a review and future perspectives. Popul Ecol 57:347-354. https://doi.org/10.1007/s10144-014-0448-z

Nowakowski AJ, Whitfield SM, Eskew EA et al (2016) Infection risk decreases with increasing mismatch in host and pathogen environmental tolerances. Ecol Lett 19:1051-1061. https://doi. org/10.1111/ele.12641

Ockendon N, Baker DJ, Carr JA et al (2014) Mechanisms underpinning climatic impacts on natural populations: altered species interactions are more important than direct effects. Glob Chang Biol 20:2221-2229. https://doi.org/10.1111/gcb.12559

Ojala R, Huhta V (2001) Dispersal of microarthropods in forest soil. Pedobiologia (Jena) 45:443-450. https://doi. org/10.1078/0031-4056-00098

Petchey OL, McPhearson PT, Casey TM, Morin PJ (1999) Environmental warming alters food-web structure and ecosystem function. Nature 402:69-72. https://doi.org/10.1038/47023

Pincebourde S, Casas J (2015) Warming tolerance across insect ontogeny: influence of joint shifts in microclimates and thermal limits. Ecology 96:986-997. https://doi.org/10.1890/14-0744.1.sm

Puentes A, Torp M, Weih M, Björkman C (2015) Direct effects of elevated temperature on a tri-trophic system: Salix, leaf beetles and predatory bugs. Arthropod Plant Interact 9:567-575. https:// doi.org/10.1007/s11829-015-9401-0

R Core Team (2016) R: A language and environment for statistical computing. R Foundation for Statistical Computing, Vienna, Austria. Version 3.3.1. https://www.r-project.org/

Rahmstorf S, Coumou D (2011) Increase of extreme events in a warming world. Proc Natl Acad Sci 108:17905-17909. https://doi. org/10.1073/pnas.1101766108

Rosenblatt AE, Schmitz OJ (2016) Climate change, nutrition, and bottom-up and top-down food web processes. Trends Ecol Evol 31:965-975. https://doi.org/10.1016/j.tree.2016.09.009

RStudio Team (2015) RStudio: integrated development for R. RStudio, Inc., Boston. Version 1.0.143. http://www.rstudio.com/

Samu F, Toft S, Kiss B (1999) Factors influencing cannibalism in the wolf spider Pardosa agrestis (Araneae, Lycosidae). Behav Ecol Sociobiol 45:349-354. https://doi.org/10.1007/s002650050

Scheffers BR, Edwards DP, Diesmos A et al (2014) Microhabitats reduce animal's exposure to climate extremes. Glob Chang Biol 20:495-503. https://doi.org/10.1111/gcb.12439
Sentis A, Hemptinne J-L, Brodeur J (2013) Effects of simulated heat waves on an experimental plant-herbivore-predator food chain. Glob Chang Biol 19:833-842. https://doi.org/10.1111/gcb.12094

Sunday JM, Bates AE, Dulvy NK (2011) Global analysis of thermal tolerance and latitude in ectotherms. Proc R Soc B 278:18231830. https://doi.org/10.1098/rspb.2010.1295

Sutherland WJ, Freckleton RP, Godfray HCJ et al (2013) Identification of 100 fundamental ecological questions. J Ecol 101:58-67. https://doi.org/10.1111/1365-2745.12025

Terblanche JS, Sinclair BJ, Klok CJ et al (2005) The effects of acclimation on thermal tolerance, desiccation resistance and metabolic rate in Chirodica chalcoptera (Coleoptera: Chrysomelidae). J Insect Physiol 51:1013-1023. https://doi.org/10.1016/j. jinsphys.2005.04.016

Terblanche JS, Deere JA, Clusella-Trullas S et al (2007) Critical thermal limits depend on methodological context. Proc R Soc B 274:2935-2942. https://doi.org/10.1098/rspb.2007.0985

Tylianakis JM, Didham RK, Bascompte J, Wardle DA (2008) Global change and species interactions in terrestrial ecosystems. Ecol Lett 11:1351-1363. https://doi.org/10.1111/j.1461-0248.2008.01250.x

van Dooremalen C, Berg MP, Ellers J (2013) Acclimation responses to temperature vary with vertical stratification: implications for vulnerability of soil-dwelling species to extreme temperature events. Glob Chang Biol 19:975-984. https://doi.org/10.1111/gcb.12081

van Heerwaarden B, Kellermann V, Sgrò CM (2016) Limited scope for plasticity to increase upper thermal limits. Funct Ecol 30:19471956. https://doi.org/10.1111/1365-2435.12687

van Wingerden WKRE, den Hollander J (1981) Ecology of arthropods living on the wadden sea islands. In: Report 10: Terrestrial and freshwater fauna of the Wadden Sea area, Final report of the section "Terrestrial Fauna" of the Wadden Sea Working Group. pp 32-127

Vasseur DA, McCann KS (2005) A mechanistic approach for modeling temperature-dependent consumer-resource dynamics. Am Nat 166:184-198. https://doi.org/10.1086/431285

Violle C, Navas M-L, Vile D et al (2007) Let the concept of trait be functional! Oikos 116:882-892. https://doi. org/10.1111/j.2007.0030-1299.15559.x

Violle C, Enquist BJ, McGill BJ et al (2012) The return of the variance: intraspecific variability in community ecology. Trends Ecol Evol 27:244-252. https://doi.org/10.1016/j.tree.2011.11.014

Voigt W, Perner J, Davis AJ et al (2003) Trophic levels are differentially sensitive to climate. Ecology 84:2444-2453. https://doi. org/10.1890/02-0266

Walther G-R (2010) Community and ecosystem responses to recent climate change. Philos Trans R Soc London B Biol Sci 365:20192024. https://doi.org/10.1098/rstb.2010.0021

Woods HA, Dillon ME, Pincebourde S (2015) The roles of microclimatic diversity and of behavior in mediating the responses of ectotherms to climate change. J Therm Biol 54:86-97. https://doi. org/10.1016/j.jtherbio.2014.10.002

Zizzari ZV, Ellers J (2014) Rapid shift in thermal resistance between generations through maternal heat exposure. Oikos 123:13651370. https://doi.org/10.1111/oik.01496

Zizzari ZV, van Straalen NM, Ellers J (2016) Transgenerational effects of nutrition are different for sons and daughters. J Evol Biol 29:1317-1327. https://doi.org/10.1111/jeb.12872 